COMPETITOR: Jurnal Pendidikan Kepelatihan Olahraga

Volume 13 Number 1 Year 2021

e-ISSN: 2657-0734 \& p-ISSN: 2085-5389

This work is licensed under a Creative Commons Attribution 4.0 International License

\title{
Influence of Triceps Overhead Extension Exercise with the Pyramid System Method on the Increased Arm Power and Long Pass Results of Water Polo Sports
}

\author{
Starlet Viersa Utami \\ Postgraduate program/Indonesian Education University/West Java/Indonesia \\ J1. Dr. Setiabudhi No.229, Isola, Kec. Sukasari, Bandung City, West Java, 40154 \\ starletviersautami@gmail.com
}

Received: December 23, 2020; Reviewed: January 03, 2021; Accepted: January 19, 2021; Published: February 28, 2021

\begin{abstract}
In the water polo sport, several techniques must be mastered, one of which is the passing technique. A water polo player must be able to throw, both at close range and long-distance. The purpose of this study was to determine the effect of triceps overhead extension training with the pyramid system method on the increase in arm power and the results of long pass water polo. The research method that I use to test the hypothesis in this study is an experimental method. In this study, the population and sample used were all female athletes of water polo in West Java with 12 athletes because these athletes were still active and the majority had understood the basic techniques of passing and long pass movements. The form of training to increase arm power and the results of long pass water polo is given by weight training triceps overhead extension with the pyramid system method. The treatment was given in 16 meetings to 12 West Java female water polo athletes. The data analysis technique used was the t-test at the 95\% significance level. Based on the results of data processing, the researcher concluded that the exercise treatment had a significant effect on increasing arm power and the results of the long pass water polo from the initial test data obtained with an average of 386.08 and the final test data of 421.33 for arm power. while for the long pass data, the average of the initial test was 17.21 and the final test was 18.01.
\end{abstract}

Keywords: Water Polo; Weight Training; Power Arm; Long Pass.

\section{INTRODUCTION}

Water polo sport is one of the aquatic sports that has been competed for a long time in Indonesia, even this sport has been completed in the 1948 National Sports Week (PON-I) in Solo, to regional, national, and international multi-event matches (Sea Games, Asian Games, Olympic Games, and World Championship) to date. Water polo is a team water sport that can be considered a combination of swimming, wrestling, football, and basketball (Britannica, 2019). Water polo is a sport with increasing worldwide interest, primarily for research purposes, with a marked increase in the number of recent publications (Del et al., 2017). One of the techniques that must be 
Influence of Triceps Overhead Extension Exercise with the Pyramid System Method on the Increased Arm Power and Long Pass Results of Water Polo Sports

mastered by a water polo athlete is the passing technique. There are two forms of passing in water polo. The first is the dry pass and the second is the wet pass. A dry pass is a form of passing where a person passes the ball and places it in his partner's hand and the ball should never touch the water. Meanwhile, the wet pass is a form of passing where someone passes the ball and places it in the water near a teammate or the area of his teammate. They must be able to pass the ball and place it squarely in the hands and the area of their friends. Sometimes a water polo athlete while training or while competing, often make mistakes when passing the ball long (long pass) to his teammates to result in the ball being captured by his opponent. In addition to mastering basic techniques (long passing), other aspects that are very influential in long passing are also needed, namely physical conditions.

Physical condition in the world of sports achievement is a very important thing because to get a good achievement one must have a good physical condition as well. The physical condition consists of basic components, including strength, endurance, flexibility, and speed. Meanwhile, to improve the physical condition. According to (Sidik, 2010) that when doing long passing, shooting at goal, and others, fast power is needed. Power is a combination of two components, namely strength, and speed. (Harsono, 1988) states that: "Power is the ability of the muscles to exert maximum strength in a very fast time". From this opinion, it is known that power has two important components that build it, namely maximum strength and very fast time. Power training can also be done with weight training. By having good power, you can determine the distance of the ball that is thrown so that it produces a good long throw. Triceps Overhead Extension is a form of weight training that functions to increase arm power, especially the triceps muscles. There are still many kinds of exercises that can be used to train arm power. It's just that here the researchers put more emphasis on increasing arm power, especially the triceps muscle. For the load itself, here the researcher uses a dumbbell to adjust the load when carrying out the exercise.

The pyramid system method is a method of increasing the load on each set and reducing the reps in each set. Regarding this system, Sidik (2008) explains that: "System pyramid: starting from the low intensity with a lot of repetitions (hypertrophy) and ending with high intensity with few reps (KI)". The advantages of the pyramid system are: (1) Using the principle of the relationship between the weight of the load and the ability to re-lift, (2) Increasing each set of loads, thereby directing even greater power. Starting from the description above, the authors are interested in researching what extent 
Influence of Triceps Overhead Extension Exercise with the Pyramid System Method on the Increased Arm Power and Long Pass Results of Water Polo Sports

Starlet Viersa Utami

starletviersautami@gmail.com

the increase in arm muscle power using the pyramid system method in the form of overhead triceps exercises.

\section{METHOD}

In this study, researchers used a quantitative approach. According to Sugiyono (2016) explains "Quantitative Research Methods are research data in the form of numbers and analysis using statistics". The research method that I use to test the hypothesis in this study is experimental. Experimental research can be defined as the research method used to find the effect of certain treatments on others under controlled conditions. This method is used to determine the results when additional treatments or exercises have been carried out. In this study, the population and sample used were all female athletes of water polo in West Java with 12 athletes because these athletes were still active and the majority had understood the basic techniques of passing and long pass movements. For the instrument, it uses the arm power test (two hands medicine ball-put) which has a validity of 0.77 and a reliability of 0.81 , as well as a water polo long-throw test. The test was carried out at the beginning and the final test of the experiment to know the initial test results and how much the increase and difference in arm power and the long pass results from the results of overhead triceps weight training using the pyramid system method.

\section{RESULTS AND DISCUSSION}

Data collected through a measurement process then processed and analyzed using a statistical approach. The results of data processing and analysis will be described in the tables below:

Table 1.

Results of Preliminary Test Scores Two-Hand Medicine Ball-Put

\begin{tabular}{ccc}
\hline Test Form & Average Value & Standard Deviation \\
\hline Two Hands Medicine Ball-Put & 386,08 & 46,11 \\
Long Pass & 17,21 & 1,80 \\
\hline
\end{tabular}

Table 1 shows that the mean score of the Two Hands Medicine Ball-Put initial test was 386.08 with a standard deviation of 46.11 , while the average Long Pass initial test score was 17.21 with a standard deviation of 1.80 .

Table 2.

Results Final Test Scores Two-Hand Medicine Ball-Put

\begin{tabular}{ccc}
\hline Test Form & Average Value & Standard Deviation \\
\hline Two Hands Medicine Ball-Put & 421,33 & 46,28 \\
Long Pass & 18,01 & 1,78 \\
\hline
\end{tabular}


Influence of Triceps Overhead Extension Exercise with the Pyramid System Method on the Increased Arm Power and Long Pass Results of Water Polo Sports

Starlet Viersa Utami

starletviersautami@gmail.com

Table 2 shows that the mean score of the Two Hands Medicine Ball-Put final test was 421.33 with a standard deviation of 46.28 , while the average Long Pass pre-test score was 18.01 with a standard deviation of 1.78 .

\begin{tabular}{|c|c|c|c|c|c|c|c|c|c|c|c|c|}
\hline 600 & \multicolumn{8}{|c|}{ Tes Power Lengan } & & \multirow{2}{*}{$-n$} \\
\hline 400 & & & & & & & & & & & & \\
\hline 300 & & & & & & & & & & & & \\
\hline 200 & & & & & & & & & & & & \\
\hline 100 & & & & & & & & & & & 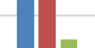 & \\
\hline 0 & Risma & $\begin{array}{c}\text { Nyoma } \\
\mathrm{n}\end{array}$ & Hanna & Inez & Ivy & Upiet & $\begin{array}{c}\text { Ayudy } \\
\text { a }\end{array}$ & Dinda & Aenah & Dean & $\begin{array}{c}\text { Nabila } \\
\mathrm{h}\end{array}$ & Anisa \\
\hline - tes awal & 362 & 398 & 420 & 374 & 373 & 440 & 345 & 497 & 352 & 374 & 360 & 338 \\
\hline tes akhir & 396 & 434 & 478 & 402 & 398 & 470 & 385 & 525 & 391 & 405 & 402 & 370 \\
\hline gains & 34 & 36 & 58 & 28 & 25 & 30 & 40 & 28 & 39 & 31 & 42 & 32 \\
\hline
\end{tabular}

Image 1.

Improved graphs Preliminary Tests and Test End Two-Hand Arm Power Medicine Ball-Put

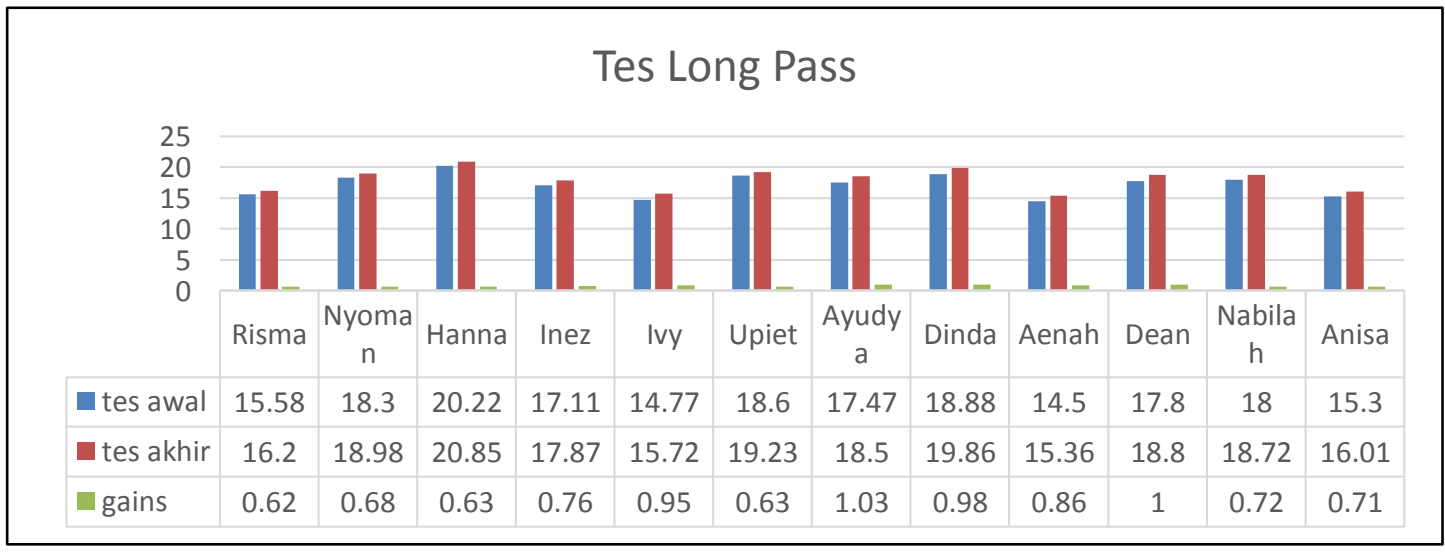

Image 2.

Water Polo Long Pass Early Test Improvement Graph

The graph above shows the results of the preliminary test, the final test of the power of the arms for two hands medicine ball-put and long pass water polo. The average of all athletes who throws two hands medicine ball-put and long pass experienced a significant increase.

Table 3.

Normality Test Results Test Liliefors Two Hands Medicine Ball-Put and Long Pass Water Polo

\begin{tabular}{cccc}
\hline Test Form & Lo & Lt & Explanation \\
\hline Two Hands Medicine Ball-Put & 0,143 & 0,242 & Normal \\
Long Pass & 0,189 & 0,242 & Normal \\
\hline
\end{tabular}


Influence of Triceps Overhead Extension Exercise with the Pyramid System Method on the Increased Arm Power and Long Pass Results of Water Polo Sports

Based on Table 3 the calculation results of the Two Hands Medicine Ball-Put test show the largest absolute number Lo $=0.143$ while $\mathrm{L}$ table with $\mathrm{n}=12$, equal to 0.242 at the 0.05 significant level. Therefore Lo $(0.143)<\operatorname{Lt}(0.242)$, then Ho is accepted and the conclusion is that the population is normally distributed. Based on the results of the Long Pass calculation, it shows that the largest absolute number is Lo $=0.189$ while $\mathrm{L}$ table with $\mathrm{n}=12$, which is $=0.242$ at a significant level of 0.05 . Therefore Lo $(0.189)<\mathrm{Lt}$ (0.242), then Ho is accepted and the conclusion is that the population is normally distributed.

Table 4.

Significance Test Results Using Arm Power Test

\begin{tabular}{cccc}
\hline Test Form & $\mathbf{t}_{\text {count }}$ & $\mathbf{t}_{\text {table }}$ & Explanation \\
\hline Two Hands Medicine Ball-Put & 13,7 & 2,20 & Significant \\
\hline
\end{tabular}

Based on Table 4 the calculation and significance test for the improvement in the results of the two forms of the test were carried out using the two-party similarity test mean $t$ test. From the test results, it is found that the Two Hands Medicine Ball-Put $t$ count $=13.7$ which is greater than the t-table at the significance level $\alpha=0.05$ with $\mathrm{dk}$ (n $-1)=11$, the price of $t(0.975)$ from the list the $t$ distribution is 2.20 . The test criterion is, accept Ho if $t<t 1-1 / 2 \alpha$. Then $t$ is in the area of Ho's rejection, so Ho is rejected. The conclusion is that there is a significant effect of overhead extension triceps exercise using the pyramid system method that is significant on the increase in arm power and the results of long pass water polo.

Table 5.

Significance Test Results Using the Water Polo Long Pass Test

\begin{tabular}{cccc}
\hline Test Form & $\mathbf{t}_{\text {count }}$ & $\mathbf{t}_{\text {table }}$ & Explanation \\
\hline Long Pass & 20 & 2,20 & Significant \\
\hline
\end{tabular}

Based on Table 4 the calculation and significance test for the improvement in the results of the two forms of the test were carried out using the two-party similarity test mean t-test. From the test results, it is found that the Two Hands Medicine Ball-Put $t$ count $=13.7$ which is greater than the t-table at the significance level $\alpha=0.05$ with DK $(n-1)=11$, the price of $t(0.975)$ from the list the $t$ distribution is 2.20 . The test criterion is, accept Ho if $t<t 1-1 / 2 \alpha$. Then $t$ is in the area of Ho's rejection, so Ho is rejected. The conclusion is that there is a significant effect of overhead extension triceps exercise using 
Influence of Triceps Overhead Extension Exercise with the Pyramid System Method on the Increased Arm Power and Long Pass Results of Water Polo Sports

the pyramid system method that is significant on the increase in arm power and the results of long pass water polo.

\section{Discovery Discussion}

After conducting research and data analysis, the findings that the researchers found in this study were:

1. The hypothesis which states that the triceps overhead extension exercise using the pyramid system method can increase the arm power of West Java Water Polo athletes is acceptable. This is following the results of the t-count calculation of arm power that is greater than the t-table.

2. The hypothesis which states that there is an effect of triceps overhead extension training with the pyramid system method with the long pass results of West Java female water polo athletes is acceptable. This is following the results of the t-count which is greater than the t-table.

The increase in arm power and the results of the long pass was due to continuous training, namely the overhead extension triceps exercise using the pyramid system method. Arms have a very important role in almost all sports, both individual and team sports. Arms have a very large contribution to achieving an achievement. In the water polo sport, the arm functions to support the techniques in water polo, such as shooting, passing, and changing directions, or moving places quickly when swimming.

Arm power training can be done with weight training either with internal resistance or external resistance. Harsono (1988, p. 185) states that: "Weight training is a systematic weight training that is only used as a tool to increase muscle strength to achieve certain goals". In weight training, several tools and forms of exercise can be used to train arm power, including bench press, triceps overhead extension, biceps curl, and so on. In training arm power for long passing, many training methods are used, one of which is the triceps overhead extension exercise.

There are many forms of exercises in increasing arm power, including using the triceps overhead extension exercise with the pyramid system method. According to Sidik (2008, p.35) states that: "System pyramid is maximum strength training starting from the low intensity with lots of repetitions (hypertrophy) and ending with high intensity with few reps (KI)". In the triceps overhead extension exercise with the pyramid system method, it is believed to be able to increase the ability of the arm power with its controlled implementation. This exercise uses weights from light to heavy. This means 
Influence of Triceps Overhead Extension Exercise with the Pyramid System Method on the Increased Arm Power and Long Pass Results of Water Polo Sports

that the longer the leg muscles are stimulated for strength training because training with heavy weights and few reps will produce strength.

The author uses the pyramid system method because this method has advantages seen from the physiological point of view (adaptation), namely starting with a light load and going to a heavy load will benefit the muscles in accelerating adaptation in starting training with heavy loads. Joycevedral, (2010, p.1) quoted by Fitriani (2011, p.24) said that: "It has taken bodybuilders years to discover that this is the optimum way to trick the muscle into working their hard esteem and making the most. progress without straining them with boredom ". The purpose of the quote above is that using exercises with a pyramid system of muscles will work optimally so that there is progress, in terms of increasing it shows changes in intensity, in other words, this pyramid system trains more muscle endurance and makes muscles work optimally.

From the explanation above, it can be concluded that the triceps overhead extension exercise with the pyramid system method has a significant effect on the increase in arm power and the results of the long pass water polo. As explained by Harsono (2001, p.41): "The best way to develop maximum power in a certain muscle group is to stretch (lengthen) the muscles first. (eccentric contraction) before contracting (shortening) the muscles explosively (concentric contraction)".

However, it needs to be realized that the use of this method must be adapted to the condition of the athlete, the norms of training loading, and the training stages, because of the importance of a scientific approach in every training load.

\section{CONCLUSIONS AND SUGGESTIONS}

Based on the results of data processing and score analysis from weight training triceps overhead extension exercises with the pyramid system method to increase arm power and the results of long pass water polo as described in chapters III and IV, the authors will conclude from the results of this study as follows:

There is a difference in the effect of weight training triceps overhead extension training with the pyramid system method on the increase in arm power and the results of the long pass water polo. Based on the data obtained in the study, weight training overhead extension triceps exercises using the pyramid system method have a significant effect on the increase in arm power and the results of long pass water polo.

Suggestions that the author can put forward about the results of this study are as follows: 
Influence of Triceps Overhead Extension Exercise with the Pyramid System Method on the Increased Arm Power and Long Pass Results of Water Polo Sports

1. For trainers and athletes of water polo that weight training overhead extension triceps with the pyramid system method can increase arm power and the results of long pass water polo.

2. For water polo coaches, coaches, and athletes to try various other methods and forms of weight training. However, it needs to be realized that the use of training methods that will be provided to athletes must be adapted to the condition of the athlete, the norms of training loading, and the training stages, because of the importance of a scientific approach in every training load.

3. For the trainer, give physical exercises systematically and repeatedly according to training principles.

4. For fellow students who will research the effect of exercise on the development of physical abilities, the author recommends trying other forms or methods of physical exercise following the demands of the training conditions.

5. For readers in general, to absorb the essence of this research and be able to benefit from this research.

\section{REFERENCES}

Britannica, T. E. of E. (2019). Water Polo. In Britannica.

Del, M., Iglesias, C., Ordóñez, E. G., Touriño, C., Iglesias, C., Ordóñez, E. G., \& Touriño, C. (2017). Keys to Success in High Level Water Polo Teams Keys to Success in High Level Water Polo Teams. 8668 (September). https://doi.org/10.1080/24748668.2016.11868944

Fitriani F. (2015) Pengaruh Latihan Plyometrics Terhadap Peningkatan Power Tungkai dan Hasil Lompat Jauh Gaya Jongkok. Skripsi Sarjana Pendidikan Pada FPOK UPI Bandung.

Harsono. (1988). Coaching dan Aspek- Aspek Psikologi dalam Coaching. Bandung: Penerbit CV. Tambak Kusuma.

Harsono. (2001). Latihan Kondisi Fisik. Bandung: Penerbit CV. Tambak Kusuma.

Sidik. D. Z. (2008) Pembinaan Kondisi Fisik Dasar dan Lanjutan. Bandung FPOK-UPI.

Sidik. D. Z. (2010). Pembinaan Kondisi Fisik. Bandung: FPOK UPI.

Sugiono (2013). Metode Penelitian Kuantitatif Kualitatif dan R\&D. Bandung: Penerbit CV. ALFABETA.Gegerkalong Hilir. 